\title{
Knowledge and Perception of COVID-19 pandemic among General Population of Pakistan (Single species responsible for the COVID-19 pandemic is "us")
}

\author{
Kashif Kamran Khan ${ }^{a}$, Amber Shahzadi ${ }^{b}$ \\ a,bequip.r.d.consultants@gmail.com \\ ${ }^{a, b}$ EQUIP Research and Development Consultants \\ Multan, South Punjab Pakistan - 60000
}

\begin{abstract}
The Corona virus outbreak that has killed millions and turned the world upside down comes from the animal world. It is a human activity that enabled the virus to jump to people and experts are warning that if nothing changes many other pandemics of this kind will follow. This study aimed to have a clear understanding of the knowledge and perception of COVID-19 among the general population of Pakistan. A cross-sectional, web-based study was conducted among the general population of Pakistan to check the knowledge and perception of COVID-19 pandemic. This descriptive study demonstrates research design, a depiction of the site, sample and population, data collection, management $\&$ analysis and limitation of the study. The results of this study show that $67.8 \%$ respondents were aware regarding COVID-19.56.5\% got the information from the social media. $74.1 \%$ of participants answered that precautions are the only measure to reduce the spread of this disease and $86.2 \%$ participants were strongly agreed of quarantine which is a precautionary measure which must be followed. The prime mode of transmission of COVID-19 is from human to human. So, all types of gatherings and celebrations in groups are unsafe for this pandemic. Practice physical distancing by staying away from enormous gatherings of individuals and unnecessarily travel. Stay home if somebody feels sick. Follow public health preventive procedures that include: better to staying home when unwell; covering mouth and nose with flexed elbow or tissue when coughing or sneezing. Protect yourself and others from getting sick. We have to make policies regarding COVID-19 awareness \& prevention so that maximum population could learn about it more as there is no current treatment available to cure it.
\end{abstract}

Keywords: COVID-19, Pandemic; Precautions; Knowledge; Perception; Preventive actions; 


\section{1- Introduction}

Corona virus recently appeared in the world as the most rapidly spreading disease in the history of mankind (Singh and Singh 2020). It has brought havoc in the mortal world leading to the highest ever economic loss this world has faced. COVID-19 has exposed the health care systems of almost every country including the developed and underdeveloped ones leading to a massive health care crisis around the world (McKibbin \& Fernando, 2020; Gautam \& Hens, 2020). The disease caused by the novel corona virus first identified in Wuhan, China. Since its emergence the virus spread worldwide in just a matter of few months and was declared as a global pandemic (Buttler \& Barrientos, 2020). The magnitude of its spread and its killing capability forced most of the world to shut down its, economic and educational sectors. That led towards recession, poverty and food shortage throughout the world (Ozili and Anum 2020).

WHO was informed of cases of pneumonia of an unknown cause in Wuhan City of China on 31 December 2019. A novel corona virus was identified as the cause by Chinese authorities on 7 January 2020 and at that time it was temporarily named "2019-nCoV”.

Pakistan is a developing country with a whopping 220,892,340 population is equivalent to $2.83 \%$ of the total world population. It became prone to the disease as two cases were reported on 26 February, 2020. This surely rang the bell on the country's government as the country was forced to go in to a lock down with economic, social and educational activities were halted (Donthu \& Gustafsson, 2020). These activities divided the thought process and perception of people regarding the COVID-19. There were people who perceived this disease to be of extreme danger and potentially life ending agent (Tandon, 2020). The people who were economically weak and were highly affected by the lockdown consider of it as global propaganda and were not participating in the preventive drive initiated by the government. This led to a further spread of the disease resulting in higher number of positive cases (Allen \& Mirsaeidi, 2020)

As described by various studies impact of Covid-19 is strongly dependent upon behavior and perception and understanding of people. Due to a rapid spread of the disease and fear prevalent in the international media, there were lots of misinformation and disinformation regarding COVID-19 (Bae \& Chang 2021). This information rapidly spread through the social media, which makes it difficult for the public to judge whether which information they would trust. This misinformation gives rise to uncertainty that is further increased because of the novelty of the disease (Yıldırım et al 2021). Therefore it becomes even more important to raise awareness and spread correct and appropriate information regarding COVID-19. Various studies have displayed the effect that such pandemics can leave on social groups, such as children, medical workers, adults and students (Neuburger, and Egger 2021). These studies were based upon determination of attitudes, knowledge and anxiety among the general population but were limited to symptoms and transmission mode.

The speed and the magnitude with which COVID-19 is spreading throughout the world demands rapid assessment of the knowledge perception and understanding of this infection (Waheed et al 2020). In order to determine the 
magnitude of the spread of misinformation knowledge, perception and attitudes are key components in order to control the pandemic (Amin et al 2020). And to improve the government effectiveness of information and preventive campaigns for controlling measure (Roupa et al 2021). In order to evade the above-stated limitations, the current study was designed and implemented to determine the knowledge, attitudes and behavior towards COVID19 of the general public of Pakistan during the critical outbreak period (Eligabily et al 2021). This study may be essential for policy makers, and for promoting health education campaigns to better control the virus before the availability of a preventive vaccine. Since there is no available vaccine or effective antiviral treatment against COVID-19, the active engagement of the population in preventive behaviors is necessary. So there must be plenty of knowledge and a high level of awareness regarding COVID-19, as well as the positive attitude is vital for controlling disease (Ilesanmi et al 2020).

\section{2- Materials and Methods}

Methodologies and procedures used in conducting this study were basically designed to check the Knowledge and Perception of COVID-19 pandemic among the general population of Pakistan. This descriptive study exemplifies research design, a portrayal of the site, sample and population, data collection and management, data analysis and limitation of study.

\subsection{Research Design}

This is a web based cross-sectional study which was designed to depict results based on simple random sampling technique. After getting the results, the descriptive and explanatory procedures were followed.

\subsection{Sample size and Population}

An online self-structured and a web-based questionnaire was shared among the general population of Pakistan. 365 respondents actively participated in answering questions.

\subsection{Data Collection}

The study used a web based questionnaire, "Knowledge and Perception of COVID-19 pandemic among general population of Pakistan”. The questionnaire which contained a total of 45 items was administered in April, 2020 across Pakistan. It requested certain responses which helped in data analysis. This questionnaire is designed which was used as a tool, to be analyzed by Google Spread Sheet. 


\subsection{Ethical Considerations}

Confidentiality of personal information was maintained throughout the study by making participants' information anonymous and asking participants to provide honest answers. Eligibility of participants in this survey was voluntary and was not compensated. Electronic informed consent was shown on the initial page of the survey.

\subsection{Limitations of the Study}

There are few restrictions for this study. The validity and reliability of the responses to the questions might be statically slanted. A web based survey is not suitable for open-ended questions because there is no skilled interviewer to explore the answers of the respondents. Short time for carrying out the research study and Lesser priority for carrying out a study because of completing urgent tasks.

\section{3- Results and Discussion}

Current study depicted an initial information and perception regarding COVID-19 among the general population of Pakistan. The results depicted mixed emotions about the state and fear of COVID-19 among the public. It was certainly observed that the people were not having much clear views regarding mitigation strategies.

\subsection{Background of the respondents}

Table 1 depicts general and basic background information of the respondents participated in the survey. The survey showed that there were four age groups, minimum range started from 18 to 49 years. $63.6 \%$ respondents were between 18 -25 years, $23.8 \%$ were $26-33$ years old, $9.7 \%$ were between $34-41$ years while $2.9 \%$ were between $42-49$ years. It was observed that both gender participated in this study. $45.5 \%$ were males \& $54.5 \%$ were females responded in this study. The survey showed that $2.1 \%$ participants who did matriculation, $38.4 \%$ respondents were undergraduates, however $27.6 \%$ were graduates \& $24.9 \%$ had masters' degrees, $1.5 \%$ participants have done their M.Phil \& $\mathrm{PhD}$, while $5.5 \%$ have completed their professional degrees. It was observed that the average family size was that of $47.4 \%$ were having 3-5 family members in their houses, $41.4 \%$ were having 6-8 family members in their houses while $11.2 \%$ were having 9 or more family members in their houses. The study showed that the Marital status of participants in which $71.3 \%$ were single, $28.7 \%$ were married. The study shows Current employment of the respondents, in which $39.8 \%$ were employed, $40.8 \%$ were students, $13 \%$ were unemployed, $3.9 \%$ were daily wagers $\& 2.5 \%$ were doing their own business. The study based upon online survey was conducted in almost every province of the country. The results depicted respondents from South Punjab to be most dominant. $40.5 \%$ of the people were representing from south Punjab while the central Punjab, depicted $30.5 \%$. Least of the respondents were reported from Sindh and Capital territory. 
Table 1. Background information of respondents

\begin{tabular}{lll}
\hline Variables & Categories & Percentage \\
\hline Gender & Male & 45.5 \\
Age & Female & 54.5 \\
& Old & 2.9 \\
& Middle aged & 9.7 \\
Education & Young & 23.8 \\
& Teenaged & 63.6 \\
& Matriculation & 2.1 \\
& Under graduate & 38.4 \\
Family Size & Graduate & 27.6 \\
& Masters & 24.9 \\
& Professional & 5.5 \\
Marital Status & MPhil/PhD & 1.5 \\
& Small & 47.4 \\
Province & Middle & 41.4 \\
& Large & 11.2 \\
& Single & 71.3 \\
& Married & 28.7 \\
& South Punjab & 40.5 \\
& Central Punjab & 30.5 \\
\hline
\end{tabular}




\subsection{Socioeconomics Information}

The survey yielded a vast diversity of economics of the participants. The study represented the monthly income of participants in which $32.6 \%$ were getting less than $10000,29.3 \%$ were getting $20 \mathrm{k}-30 \mathrm{k}, 15.1 \%$ were getting $30 \mathrm{k}$ 40k, $9.5 \%$ were getting 40k-50k \& $13.5 \%$ were getting 50,000 or above. Table 2 shows the Current employment of the respondents, in which $39.8 \%$ were employed \& on their jobs, $40.8 \%$ were students, $13 \%$ were unemployed, $3.9 \%$ were daily wagers $\& 2.5 \%$ were doing their own business.

Table 2. Socioeconomics Information

\begin{tabular}{lll}
\hline Variables & Categories & Percentage \\
\hline Employment Status & Business & 2.5 \\
\cline { 2 - 3 } & job & 39.8 \\
& Daily wages & 3.9 \\
& Student & 40.8 \\
& Unemployed & 13 \\
Monthly Income & $<10000$ & 32.6 \\
& $20,000-30,000$ & 29.3 \\
& $30,000-40,000$ & 15.1 \\
& $40,000-50,000$ & 9.5 \\
& $50,000 \&$ Above & 13.5 \\
\hline
\end{tabular}

\subsection{Perception and information regarding COVID-19}

Figure 1 reflects that how long the participants know the Coronavirus outbreak in which $67 \%$ of the participants knew it three months before when started in Wuhan \& $18.5 \%$ were those who knew about it a month before when schools/colleges were off while $12.5 \%$ knew it a week before when the government put a lock down in the city. It was observed that the participant's source of information about global pandemic of the corona outbreak is from different sources like, $56 \%$ got the information from social media, 34\% got it from TV/Newspapers, $8 \%$ got it from government sources and 1\% got it from friends in China and 1\% from other friends (Fig 2). The study depicted that most of the respondents know about the COVID-19, in which $67.8 \%$ respondents select all the options, $15 \%$ told that it's a virus \& causes serious disease of a respiratory system, $10 \%$ told that its need human host for replication and spreads infection through contacts, 4\% answered that it's a large family of viruses that are known to cause illness from the common cold to severe diseases while remaining participants don't know about COVID-19 exactly (Fig 3). The study shows that $85.5 \%$ responded above all options, 5.5\% answered shortness and difficulties in breathing while 5\% replied of fever are the symptoms of someone infected with a corona virus (Fig 4). The study illustrated that $46.3 \%$ participants answered in all are correct options, $12 \%$ were replied that people with weak immune system, 20.7\% answered that mostly below years 5 and elders above 60 years died of COVID-19, 3\% thinks that anyone can in contact with it whereas $18.5 \%$ replied that people who did not take precautions can died of COVID-19 (Fig 5).

Figure 6 illustrate of 59\% participants selected all the options, 29\% replied lack of seriousness (not following governmental restrictions), $9 \%$ told lack of public awareness (no precautionary measures from the governments) 
whereas 3\% Personal habits of not keeping cleanliness was the main reason for the spread in the various part of the world. Figure 7 displays that $81.5 \%$ were strongly agreed on all types of gatherings, celebrations in groups are unsafe for this pandemic \& $13.5 \%$ were agreed on it while $1.5 \%$ didn't know about it. Figure 8 displays that $29 \%$ participants think that in case of serious patients dies of COVID-19, we should not participate in his/her funeral prayers whereas $71 \%$ were in favor to participate in his/her funeral prayers.

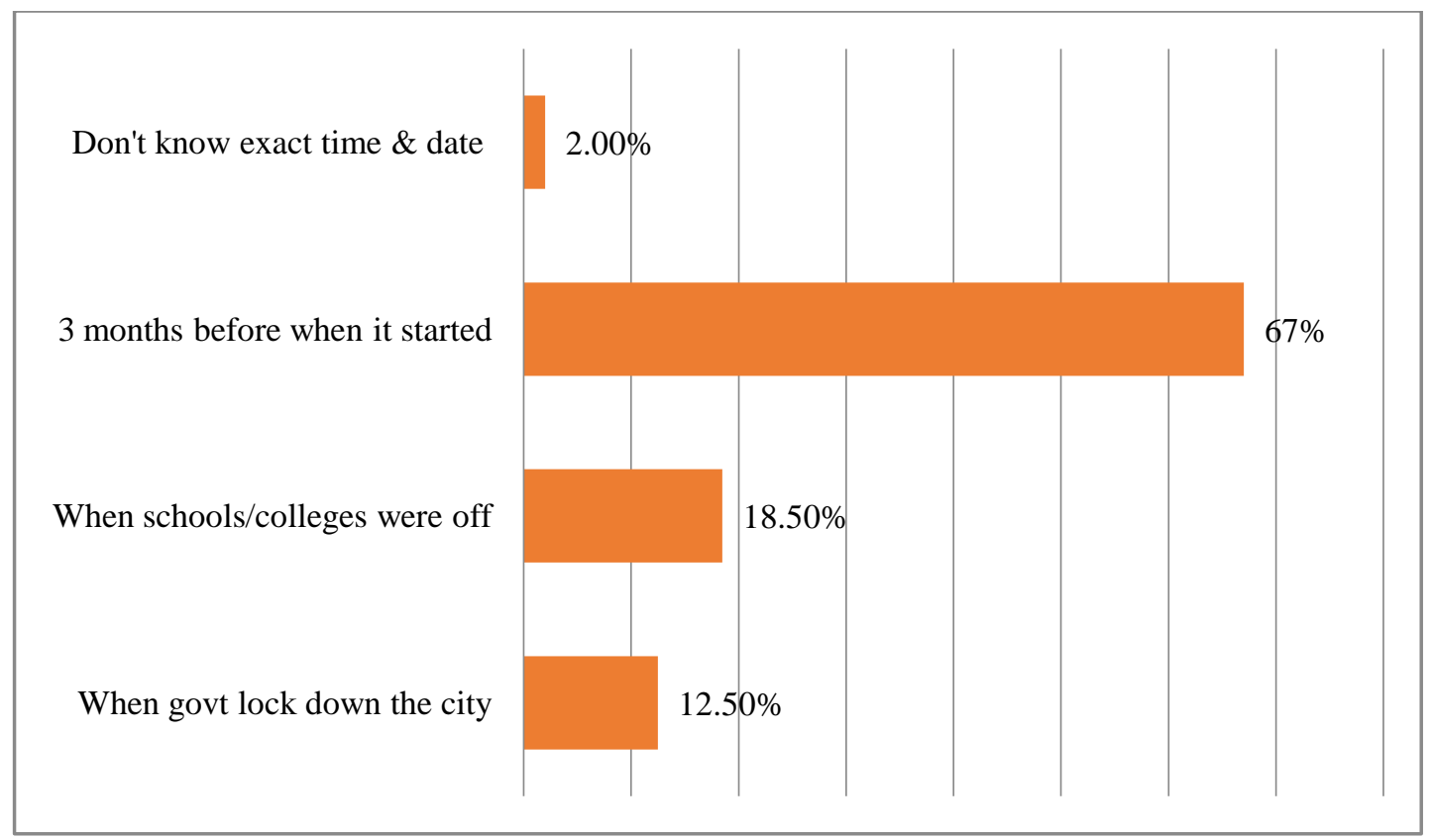

Fig 1. How long do you know the Corona virus outbreak 


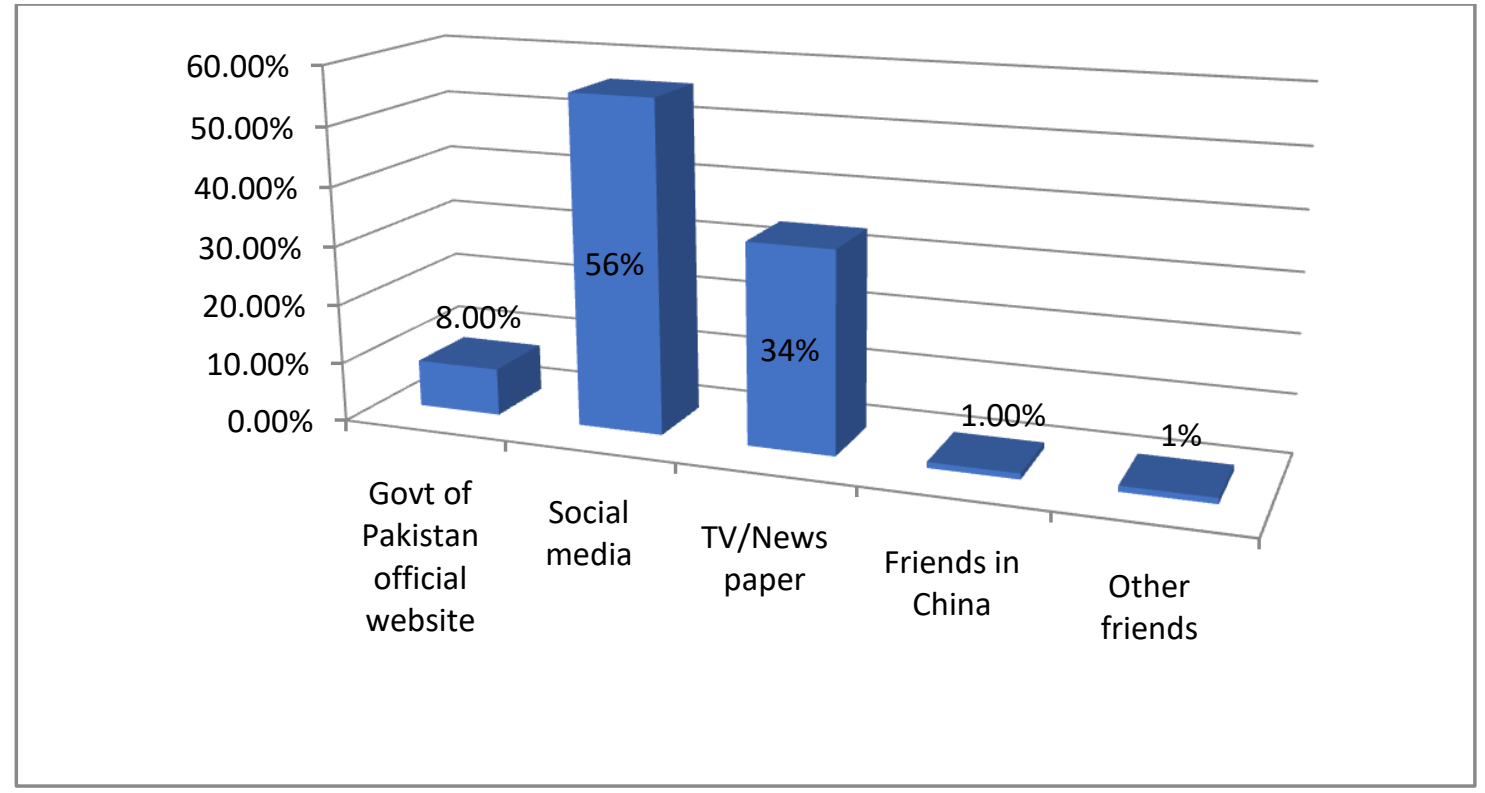

Fig 2. Source of information you got regarding COVID-19

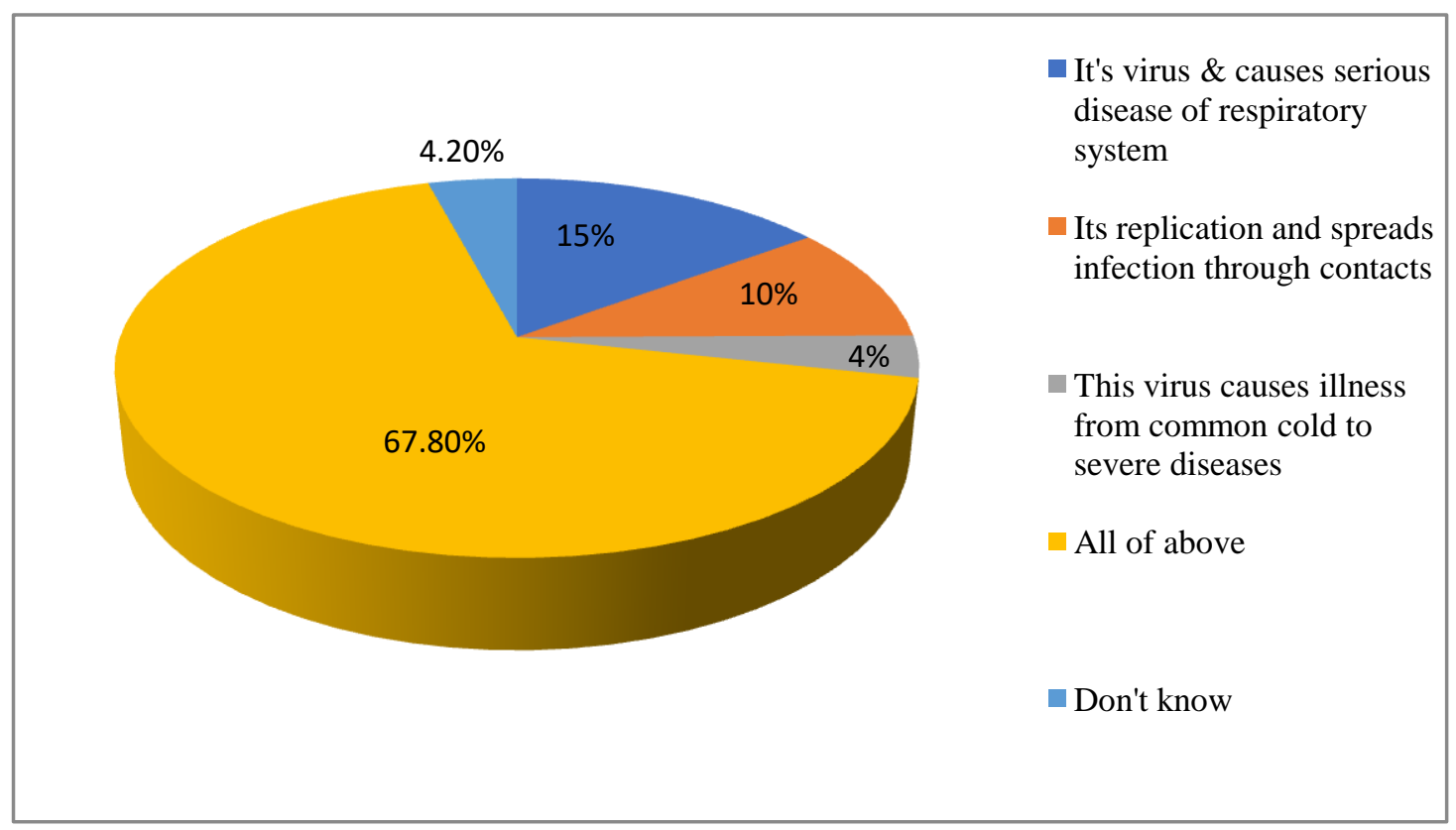

Fig 3. How much do you know about COVID-19 


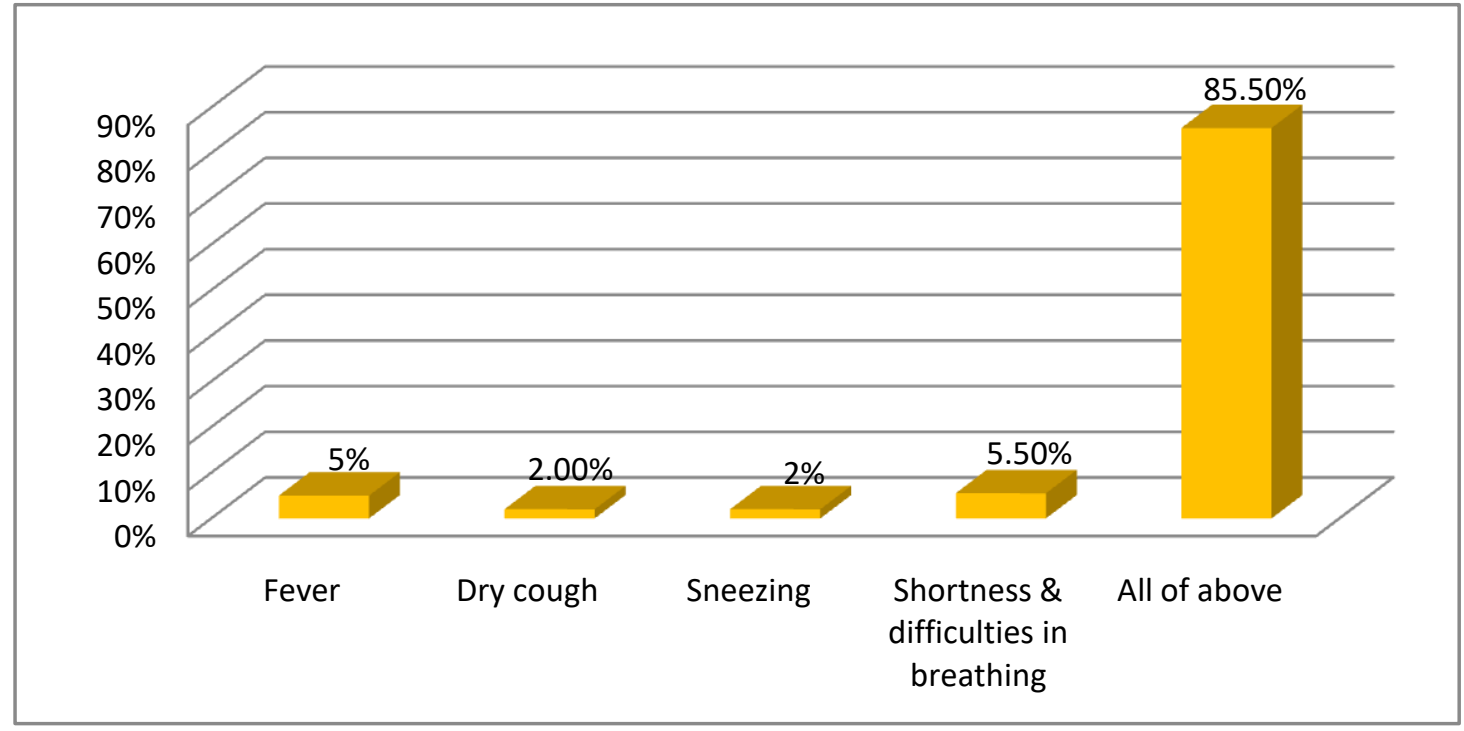

Fig 4. What are the symptoms of someone infected with a corona virus?

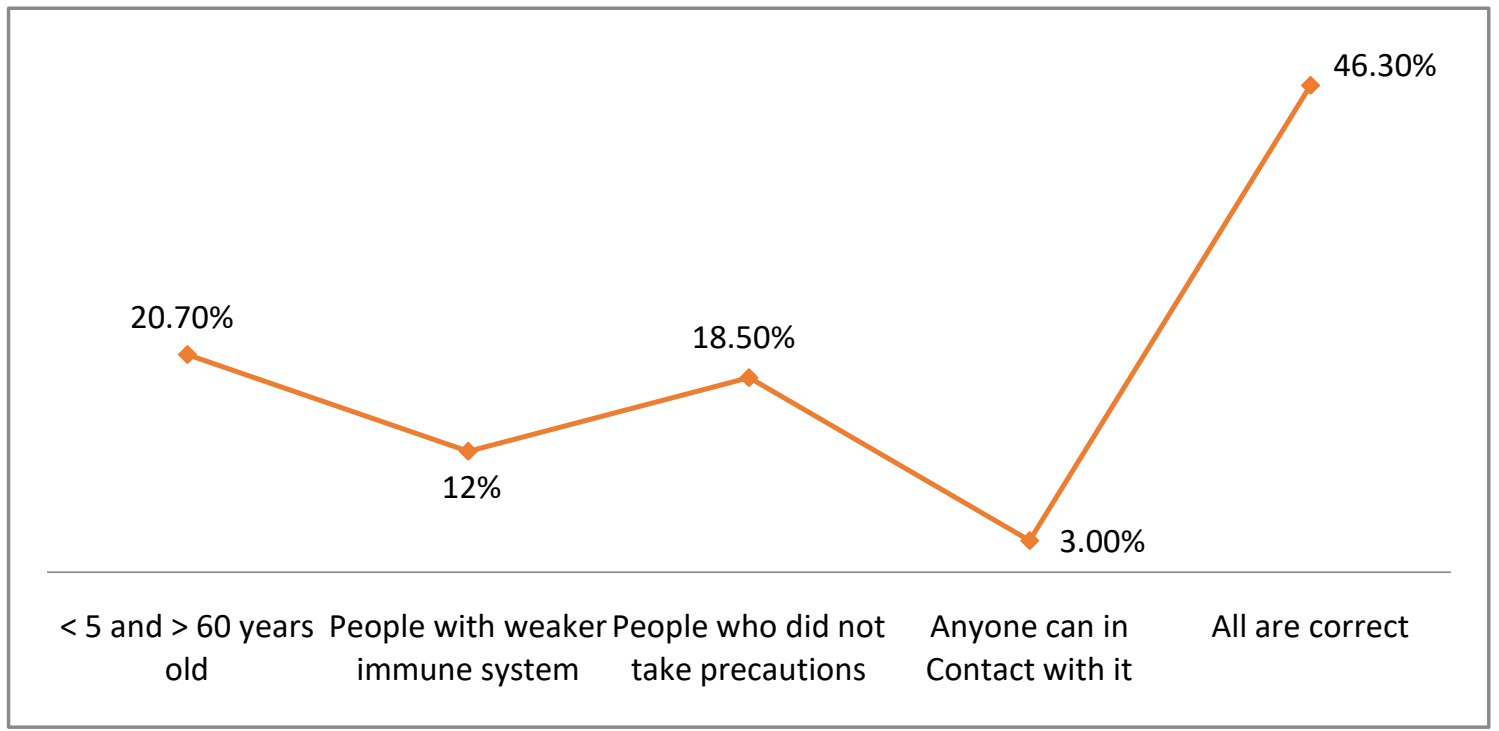

Fig 5. How much is the age of those people who died of COVID-19? 


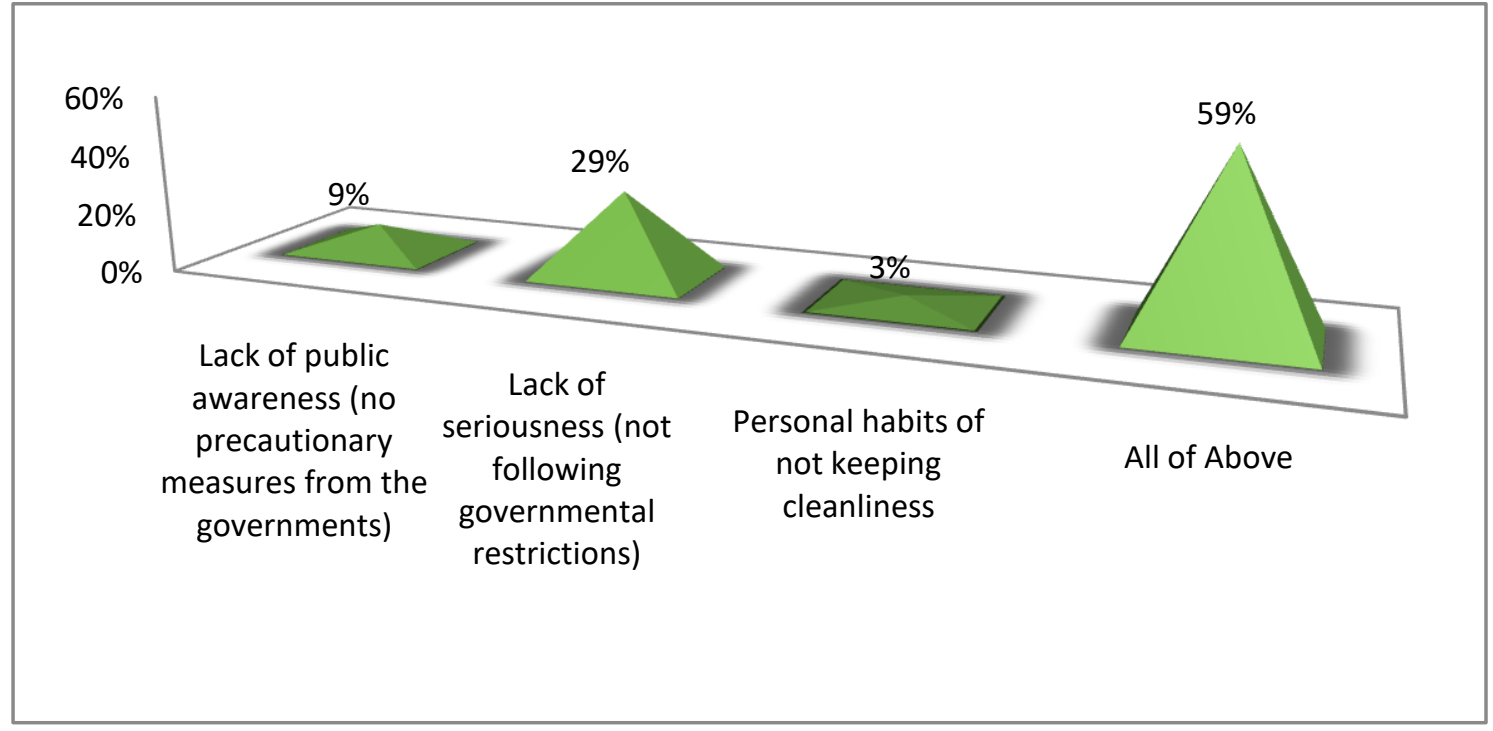

Fig 6. What is the main reason for the spread in various parts of the world?

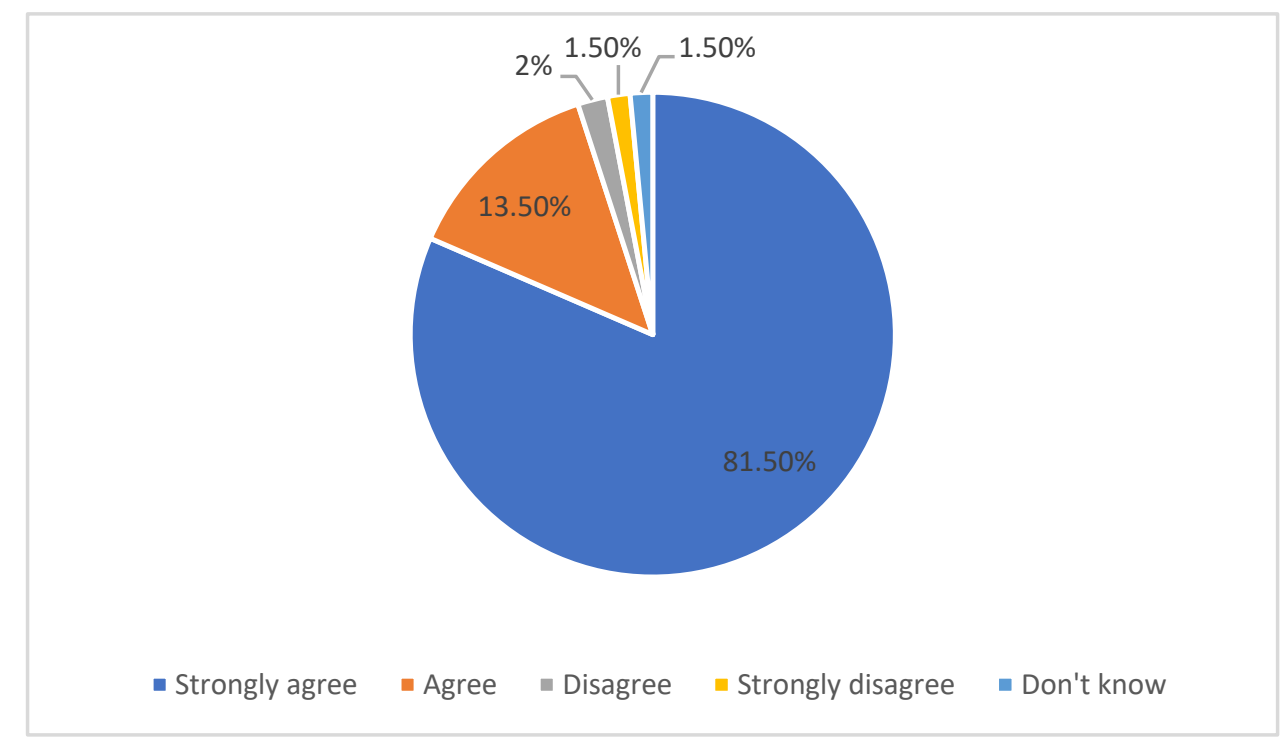

Fig 7. All types of gatherings, celebrations in groups are unsafe for this pandemic? 


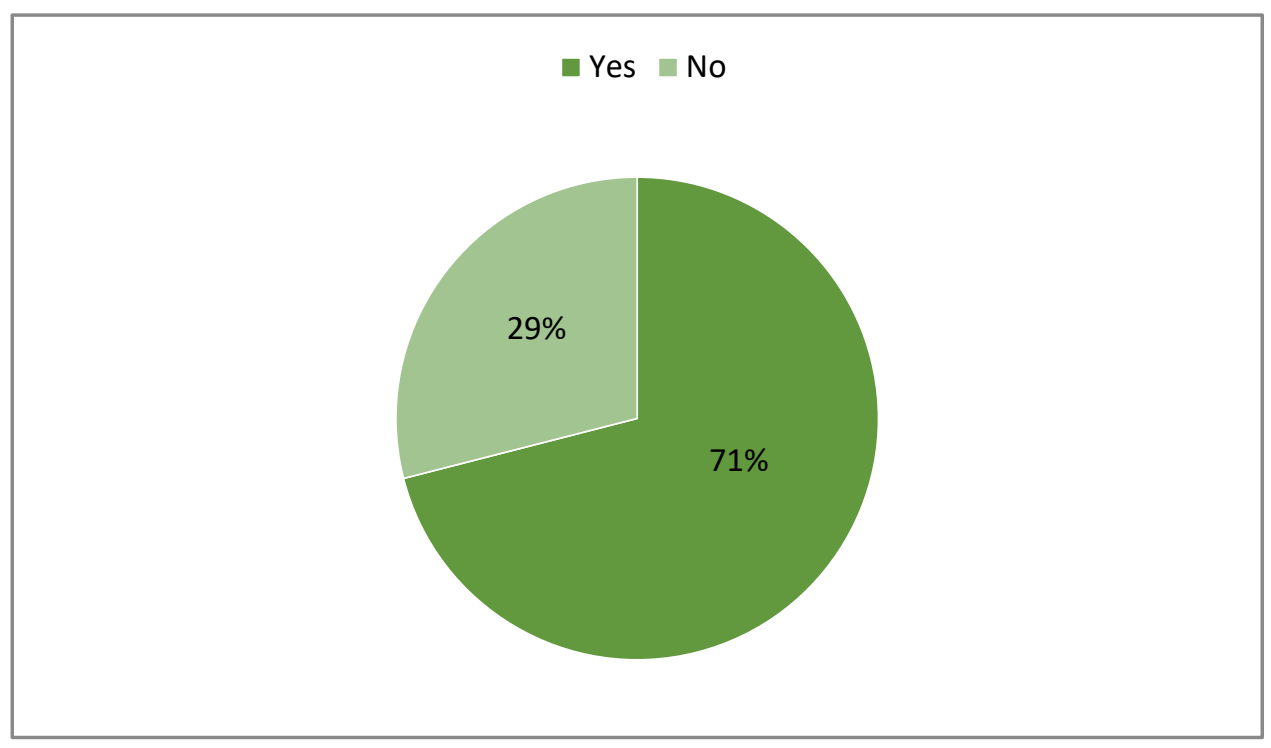

Fig 8. In case of serious patients' dies of COVID-19, will you participate in funeral prayers?

\subsection{Knowledge and Impacts of COVID 19}

The study displayed that most of the participants were aware of the disastrous impacts that the COVID-19 was causing. Figure 9 indicates, $83.2 \%$ were thinking that human can make deadly viruses that can affect the human species whereas $16.8 \%$ didn't think a human can make deadly viruses that can affect the human species. The study reflects that $49 \%$ of respondents were of the view that we should make every possible effort; however, there is no guarantee to life whereas $31 \%$ answered that our precautionary measures can get us out of this crisis while $16 \%$ of participants told that it is because of our health and immunity level \& $4 \%$ answered that our economic status can get us out of this crisis (Fig 10). Fig 11 shows that 39.4\% participants were agreed about the video on social media regarding COVID-19 are disturbing \& not to be shown whereas $31.4 \%$ respondents were disagree about this statement. It was observed that $40.8 \%$ participants were disagree since the disease has declared pandemic, I am scared and losing hope for health /life \& safety whereas $34.4 \%$ participants were agree on this statement \& $19 \%$ were strongly disagreed while $5.8 \%$ strongly agreed of the statement (Fig 12). 


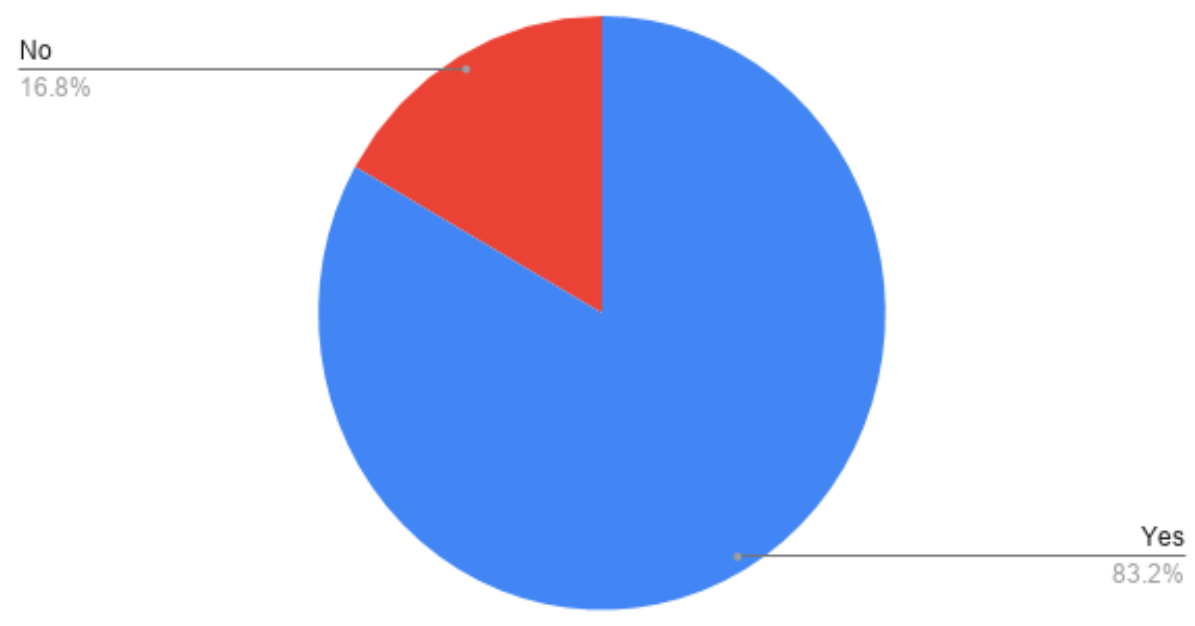

Fig 9. Humans can make more of these deadly viruses affecting the world

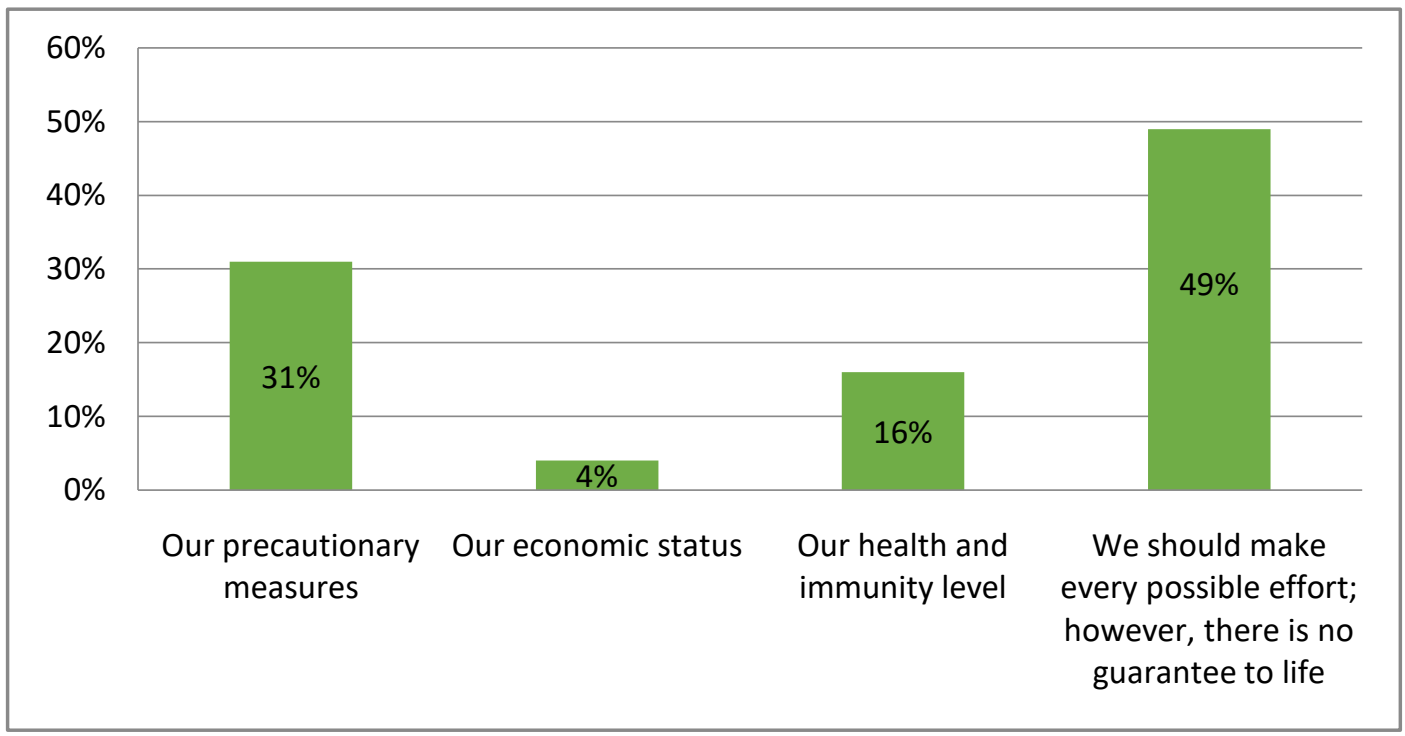

Fig 10. Which factors can get us out of this crisis 


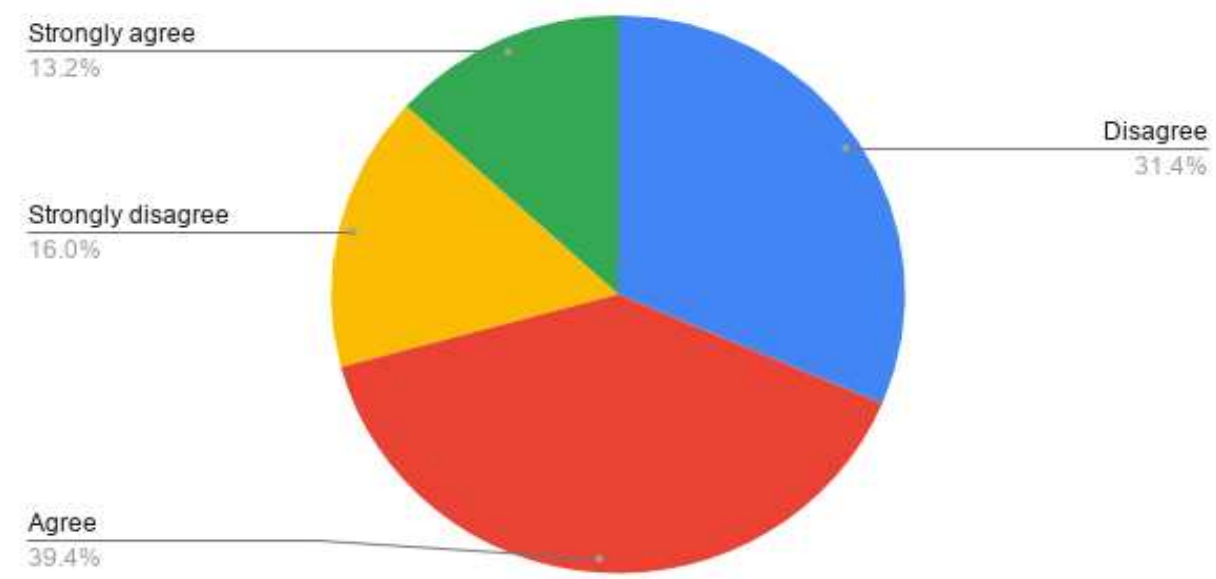

Fig 11. Videos on social media regarding COVID-19 are disturbing and not be shown

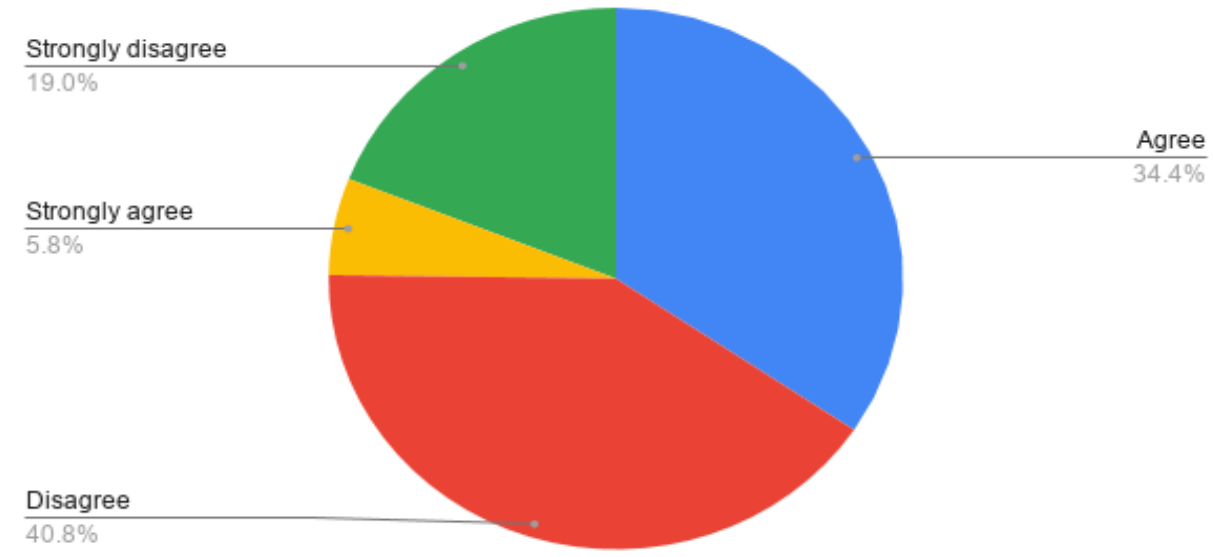

Fig 12. Since the pandemic break out people is more scared and losing hope 
Table 3. Knowledge regarding Mitigation strategies

\begin{tabular}{llc}
\hline Variables & Categories & Percentage \\
\hline Is isolation viable for Precautionary measures & Strongly Agree & 45.5 \\
& Agree & 32.5 \\
& Disagree & 15 \\
& & \\
& Strongly Disagree & 5 \\
& & \\
& Don't Know & 2 \\
Instead of lockdown government should provide & Strongly Agree & 14.8 \\
disinfectants and medical facilities to its citizens & Agree & 37.8 \\
& Disagree & 24.7 \\
& Strongly Disagree & 22.7 \\
Precautionary measures are necessary but it cannot & Strongly Agree & 20.8 \\
harm me & Agree & 35.1 \\
& Disagree & 36.4 \\
Responsibility for being safe from pandemic lies & Strongly Disagree & 7.7 \\
not only the government but also on public & Strongly agree & 75.3 \\
& Strongly disagree & 3.4 \\
& Agree & 20.3 \\
& Disagree & 1 \\
& & \\
& &
\end{tabular}

\subsection{Knowledge regarding Mitigation strategies}

The study showed that the people were little reluctant in some of the aspects of mitigating COVID-19 pandemic. It was observed that $45.5 \%$ participants were strongly agreed that quarantine/isolation is a precautionary measure \& must be followed whereas $32.5 \%$ agree on this statement while $2 \%$ didn't know how to follow it (Table 3 ). When the respondents were asked whether instead of lockdown government should provide disinfectants and medical facilities to its citizens, the study showed that $37.8 \%$ were agreed on it that instead of lockdown government should provide disinfectants and medical facilities to its citizens while $24.7 \%$ participants were disagree on this statement, but $22.7 \%$ were strongly disagreed on it while $14.8 \%$ were strongly agreed on it. It was observed that $75.3 \%$ participants were strongly agreed on the responsibility for being safe from pandemic not only lies in the government, but also on the public while $20.3 \%$ agree on it \& $3.4 \%$ strongly disagree about the statement. Table 3 displays that $36.4 \%$ of participants were disagree regarding necessary precautionary measures, but I believe that nothing can harm me and I should not be afraid of whereas $35.1 \%$ were agreed on that statement while $20.8 \%$ strongly agreed on it and $7.7 \%$ were strongly disagreed on that statement. 


\section{4- Conclusion}

The Present research was conducted in the first year of COVID-19 outbreak thus the results presented in this scenario could be somehow contrary to some of the new researches. Current study focused on the knowledge and perception of the people regarding COVID-19 pandemic. It was observed that the information about Corona virus is widespread among most age group and various sectors of the society. This information is mostly prevalent from the use of social and electronic media. The study showed that due to prevalent information the respondents had appropriate amount of knowledge regarding the symptoms and signs of the virus. The people showed significant information as per popular belief in the media of mitigating and prevention activities to be followed in order to avoid contraction of the disease.

$\mathrm{CoV}$ infections are common in animals and humans. Some strains of $\mathrm{CoV}$ are zoonotic, but many strains are not zoonotic, they can be transmitted between animals and humans. The prime route of transmission of COVID-19 is from human to human. So, all types of gatherings and celebrations in groups are unsafe for this pandemic. We should practice physical distancing by avoiding unnecessary travel and staying away from large groups of people. Stay home if you feel unwell. Follow public health preventive procedures \& actions that include: staying home when sick; covering mouth and nose with flexed elbow or tissue when coughing or sneezing. Dispose of used tissue immediately; washing hands often with soap and water; and cleaning frequently touched surfaces and objects. Protect yourself and others from getting sick.

\section{5- Recommendation}

To get a clearer \& complete picture of COVID-19, we need a tool called a serologic diagnostic (one is in development now). Rather than identifying a virus when a person is currently sick, a serologic diagnostic can detect whether a person was previously infected even after the disease has resolved. With this information, we can begin to understand the proportion of the population that is being infected over time.

The experts laid out three scenarios for how the corona virus pandemic will progress. The worst-case scenario among these three projections involves a second, larger wave of infections this fall and winter. The report authors suggest this is the most likely outcome, and states need to prepare for it. 


\section{References}

Singh, J., \& Singh, J. (2020). COVID-19 and its impact on society. Electronic Research Journal of Social Sciences and Humanities, 2. McKibbin, W., \& Fernando, R. (2020). The economic impact of COVID-19. Economics in the Time of COVID-19, 45(10.1162).

Gautam, S., \& Hens, L. (2020). COVID-19: Impact by and on the environment, health and economy.

Butler, M. J., \& Barrientos, R. M. (2020). The impact of nutrition on COVID-19 susceptibility and long-term consequences. Brain, behavior, and immunity, 87, 53-54.

Ozili, P. K., \&Arun, T. (2020). Spillover of COVID-19: impact on the Global Economy. Available at SSRN 3562570.

Donthu, N., \&Gustafsson, A. (2020). Effects of COVID-19 on business and research.

Tandon, P. N. (2020). COVID-19: Impact on health of people \& wealth of nations. The Indian journal of medical research, 151(2-3), 121.

Allen, M. B., \&Mirsaeidi, M. (2020). Health and Economy in COVID-19 Era: a plan for reconstituting long-term economic security. Frontiers in public health, 8, 235 .

Bae, S. Y., \& Chang, P. J. (2021). The effect of coronavirus disease-19 (COVID-19) risk perception on behavioural intention towards 'untact'tourism in South Korea during the first wave of the pandemic (March 2020). Current Issues in Tourism, 24(7), 1017-1035.

Yıldırım, M., Geçer, E., \&Akgül, Ö. (2021). The impacts of vulnerability, perceived risk, and fear on preventive behaviours against COVID19. Psychology, health \& medicine, 26(1), 35-43.

Neuburger, L., \& Egger, R. (2021). Travel risk perception and travel behaviour during the COVID-19 pandemic 2020: A case study of the DACH region. Current Issues in Tourism, 24(7), 1003-1016.

Wahed, W. Y. A., Hefzy, E. M., Ahmed, M. I., \&Hamed, N. S. (2020). Assessment of knowledge, attitudes, and perception of health care workers regarding COVID-19, a cross-sectional study from Egypt. Journal of community health, 45(6), 1242-1251.

Amin, F., Sharif, S., Saeed, R., Durrani, N., \&Jilani, D. (2020). COVID-19 pandemic-knowledge, perception, anxiety and depression among frontline doctors of Pakistan. BMC psychiatry, 20(1), 1-9.

Roupa, Z., Polychronis, G., Latzourakis, E., Nikitara, M., Ghobrial, S., Chrysafi, A., \&Noula, M. (2021). Assessment of Knowledge and Perceptions of Health Workers Regarding COVID-19: A Cross-Sectional Study from Cyprus. Journal of Community Health, 46(2), $251-258$.

Elgibaly, O., Daef, E., Elghazally, S. A., Hassan, H. M., ElsaidTash, R. M., Bahgat, S. M., ... \& El-Sokkary, R. H. (2021). Knowledge, perception, and confidence of healthcare workers about COVID-19 preventive measures during the first wave of the pandemic: a cross-sectional study from Egypt. Germs, 11(2), 179.

Ilesanmi, O., \&Afolabi, A. (2020). Perception and practices during the COVID-19 pandemic in an urban community in Nigeria: a cross-sectional study. PeerJ, 8, e10038. 